\title{
Future Logistics Approaches
}

\author{
A View from the U.S. Air Force ATS Policy Office
}

\author{
Betty Spofford, Julie Altham, and John Stabler \\ U.S. Air Force ATS Policy Office \\ WR-ALC/GRN, Robins AFB, GA
}

\begin{abstract}
Moving towards the future in government testing is challenging yet very exciting. With newer platforms, Built in Test (BIT) and Built in Self Test (BIST) are used much more extensively than with legacy platforms. Additionally, some of the old design philosophies we once put aside have become new again, and have gained a much wider acceptance. This includes ensuring systems, including test systems, are supportable for life without being tied to the Original Equipment Manufacturer (OEM) for every hardware and software change.
\end{abstract}

The Department of Defense (DoD) and the Air Force are actively involved in developing logistics capabilities to provide better approaches to platform systems support.

Keywords- logistics; prognostics; TPS; ATE; TPS tranportability; US Air Force; ATS; automatic test

\section{INTRODUCTION}

This paper will discuss future logistics approaches for Air Force (AF) Automatic Test Systems (ATS) from the perspective of the Air Force ATS Policy Office. The first area of discussion is the recent changes made by the AF which will impact logistics in the near future. The next area of discussion is the future. The final area of discussion is AF ATS logistics possibilities for the far future.

There are twelve Integrated Product Support (IPS) elements: Sustaining Engineering; Supply Support; Maintenance Planning and Management; Packaging, Handling, Storage, and Transportation; Technical Data; Support Equipment; Training and Training Support; Manpower and Personnel; Facilities and Infrastructure. This paper will address many of the elements as they relate to future AF ATS logistics.

There are several tools, instructions, guides, and changing environments which will influence the Air Force (AF) ATS logistics of tomorrow. These will affect how the AF buys and repairs assets for ATS as well as AF platforms. The approach to how testing will be performed, and the roles of people within the AF ATS community will have impacts on the ATS logistics of the future. What is lacking today is full visibility of all assets, full health assessment of a platform and its subsystems, easy TPS transportability, and a more standard approach to how testing is performed.

\section{ChANGES TODAY IMPACTING AIR FORCE ATS FUTURE LOGISTICS}

\section{A. The Impact of New Data Systems}

In the past, field users, shop chiefs, depots, Inventory Managers (IMs), and Program Managers (PMs) have occasionally 'hidden' necessary test capability. Shop chiefs have placed equipment in the shop ceiling or on flatbed trucks which slowly circled the base during inspections to conceal the existence of the equipment which was not on their Allowance Standard or spares for which the IM no longer had visibility. IMs and PMs pay close attention to troublesome items. Sometimes this includes holding back a few items to satisfy the most critical requirements which have historically cropped up at the most inopportune times.

Although this may seem to be a positive thing at the time, there is a down side to keeping assets which are not visible to the supply system. The field users' and depots' main thrust is to repair end items and components and make AF platforms fully mission capable. What the field and depot do not do is ensure the support logistics are in place. When this happens, or to be more precise, does not happen, the equipment will eventually break or require calibration. With no means to correct this lack of support, the test equipment will become useless.

With the implementation of the Expeditionary Combat Support System (ECSS) [1], Logistics, Installations, and Mission Support - Enterprise View (LIMS-EV) [2], and Item Unique Identification (IUID) [3], most of this will change. When implemented, these systems will provide near real-time information on where assets are located and the condition of the equipment.

With these systems all levels of management can see where the assets are; whether in the warehouse, in transit, in repair (organic or contractor), or being procured, and the quantity at each base. ECSS is the cornerstone enabler for eLog21. eLog21 is the AF umbrella strategy which integrates and governs $\mathrm{AF}$ logistics transformation initiatives to ensure the warfighter receives the right support at the right place at the right time.

The eLog21 goals are: 'Increase equipment availability to match Aircraft Availability targets and to Reduce Operations and Support (O\&S) cost by 10 percent'. Each of the USAF Air Logistics Centers (ALC) has an internal ATE database which will be connected to LIMS-EV according to the 3 May 11 
LIMS-EV policy meeting. The allowance standards and asset visibility are already part of LIMS-EV. LIMS-EV provides one central, standardized point of access to analytical information across all USAF A4/A7 resources and process areas.

With IUID, the AF should have greater visibility into what assets are truly in the field and depots as well as being able to pinpoint problem items which have a higher than normal repair rates. Every end item is to be marked (with few exceptions where it is not prudent to do so such as with animals or where it is not cost effective such as with Nuclear, Biological, and Chemical (NBC) suits for better tracking.

These systems should provide a much better insight to what is at the depot level and the health of this equipment. These systems may become valuable tools for the ATS Product Group Manager (PGM) to plan for consolidation of similar requirements which cross depots. It should also assist commanders to redistribute scarce testing capability under their purview. The data will be a prognostics enabler. Prognostics is the ability to predict when a system or part is beginning to fail or is expected to fail during a certain period of time. Knowing when a part will fail can allow the user to place a demand on the system which theoretically will allow the user to order the part in time to be in place when the part experiences a hard failure. Prognostics data will be used to target reliability improvements.

\section{B. Testability Impact on Design}

The need to include the testability of an item as it is being designed is once again being included in some of the engineering classes. This is part of the ' $\mathrm{M}$ ' in the Reliability and Maintainability ( $R$ and $M$ ) aspect of a system. The ease of accessing test points of Line Replaceable Units (LRUs) and Shop Replaceable Units (SRUs) will reduce testing times and improve diagnostics. A system designed for testability can require a TPS that is less expensive by a factor of ten than a corresponding system not properly designed for ease of test. A testable system is far easier to control and observe than a less testable system.

One area of change which will have a large logistical impact will be Built in Test (BIT) and Built in Self Test (BIST). BIT and BIST are used much more extensively in new systems than with legacy platforms. Testability, BIT, and BIST are enhancements which can be supported with extensive use of modeling and simulation.

\section{The Impact of ATS Standardization}

When ATS software is written in and ATS hardware designed in a standard manner with an open architecture, the ATS is more transportable in the future as well as easier to maintain today. It allows the government the greatest flexibility. In the past, systems have been acquired that have proprietary elements. Proprietary elements are difficult to acquire competitively and to sustain organically. The open systems can be competed or maintained organically, thus reducing acquisition and sustainment costs. When this standardization is captured in a document the platform program office can use, such as MIL-PRF-32070A "Performance
Specification, Test Program Sets"[11], it is easier for the government program office as well as the contractors to understand TPS requirements.

Using standard families of testers allows the government to expand tester configurations to encompass additional workload. Government tester configuration management, unlimited rights to the ATS software, hardware, drawings, and tech manuals, increases the ability of the government to ensure all logistics elements are addressed, sometimes by multiple vendors, and gives the flexibility to expand the design to meet a broader range of requirements, frequently at a significantly lower cost. Ensuring standard interfaces are used as part of the design allows the test system to have an open architecture. Industry specifications and standards (with government input) are used to make sure industry tools are available to implement a Modular Open Systems Architecture (MOSA) as required by DoD ATS policy [12].

ATS Architecture Framework Standards are a direct means to meet the DoD objectives for ATS modernization as directed by the ATS Management Board (AMB) Executive Director. The AMB is comprised of O-6 level members (Colonels, Navy Captains, or their civilian equivalents) from each of the services to discuss and solve DoD ATS problems. Where possible, the services provide synergy and plan multi-service solutions. As of today, the AMB is led by a Navy Executive Director.

The ATS Executive Director's stated goals are: 'improve instrument interchange, make ATE more adaptable with no penalty to requirements, faster technology insertion, improve TPS rehost, improve TPS interoperability, use model based programming techniques, modernize test programming environment, define TPS performance spec, greater use of commercial products, capture design to test data, use weapon system to test data, use knowledge based TPSs, define interfaces with the Integrated Diagnostics Framework.' [5]

The AMB Framework Working Group, a DoD AMB Integrated Product Team (IPT) who advances IEEE standards to meet these goals, has recently been working on the following standards; Prognostics/Diagnostics, IEEE 1232 which is to develop a method to include gray-scale health assessment, and Maintenance Action Information (MAI), IEEE Std 1636.2 [8] is a collection of maintenance actions and events and the data associated with operations and repair. This standard has been published and integrated into the ATML, IEEE 1671 standard [10]. The Signal and Test Definition standard, IEEE Std 16412010, has been established as a full-use IEEE standard [9]. IEEE Std 1671-2010 ATML Standard is now in full use. IEEE 1445 , which is the digital test interchange format (DTIF) has been reaffirmed. [5]

The ATS Framework standardization elements when used together allow supportability of a system by multiple sources and all logistics elements. In addition, it is easier to have testers and test systems which can be used by all the services. TPS standardization will enable the collection of prognostics data for the weapon systems Units Under Test (UUTs) as well the test systems. Knowing the reliability drivers for UUTs will help identify UUT resource requirements and potential reliability improvements. 


\section{The Impact of Changing DoD Roles and Relationships}

In the early days of ATS, the DoD was a dominant player in the test instrument industry. Now, with the rise of commercialoff-the-shelf test instruments and their wide spread use in industry, the DoD's role has diminished to less than two percent of the test equipment market. The DoD is now heavily dependent on commercial instruments for ATE components. Traditionally, a testing capability was developed by the OEM and the DoD was forever tied to the OEM for modification of the test system as well as the majority of the repair. The OEM then farmed out parts of the workload to sub-contractors based on their internal business case analysis.

The current policy is the opposite. When an OEM develops test capability, the DoD acquires full rights to the system, and performs all repair organically except for pieces of the workload which can be farmed out to sub-contractors. In the future, OEMs will no longer be fully responsible for the supportability of their systems. There are a plethora of different variations of contractor, sub-contractors, and the organic depot roles within the DoD community. The organic depots are sometimes used in the same manner the OEM uses a sub-contractor for repair or support of workloads. Organic depots have sometimes used the OEM as a sub-contractor for parts of organically identified workload.

\section{TOMORROW}

In the future, intermediate and depot repair chiefs will know the status of their ATS and when to replace ATS components, also known as Tester Replacement Units (TRUs), without significantly hindering tester availability. There would be a scheduled time, perhaps quarterly, to change out 'soon to fail' as well as broken items. At the operational level, platform prognostics allow the user to know the platform's health and how long it will likely remain healthy. Handheld (or perhaps wristwatch sized) devices will deliver maintenance and health information. The information will also identify what will go wrong and when so the replacement part can be ordered and delivered at the appropriate time rather than waiting for a hard failure.

Inventory Managers will buy and repair assets based on hard failures as they do today, but field and depots will drive short term additives to the supply system. This will allow parts to be available and in place when the user is ready to install them when identified as 'soon to be needed' due to prognostics. Having real time information on the location and condition of all assets will cut down on manual computer file maintenance which consumes a significant amount of time and is caused by the lack of trusted maintenance data. Budgets will be more realistic and based on provable facts. Hard decisions on what to buy or repair during austere funding will be a little more factual based than whom, due to better writing skills with the same level of government impact, can write the better impact statement.

Engineering will have hard information on the items with repeated problems at the tester and component level thus making it easier to know when to modify or replace a bad item or items, or patch software.
System program managers at the AF platform level will require platform design at all practical levels to include testability. Additionally, standard ATE and TPSs written in a standard manner with open architecture will also be a normal contractual requirement. Providing the platform system testing requirement to the ATS PGM as soon as it is identified will be the norm. This will be because the ATS PGM will assist in choosing the best standard equipment for the testing requirement and in time to ensure funding is available for procurement of the tester, development and production of TPSs, and all needed support elements are in place on the first day of need.

Of course contractors will continue to design and build AF platforms. They will perform major modifications to increase aircraft capability as well as address obsolescence. They will want to design in ease of testability because it will increase aircraft availability. Prognostics, BIT, and BIST will evolve to the point where a monthly or quarterly test is fast and so easy an airman out of basic training can perform these easy yet critical tests. Contractors will strive to find or use materials which do not wear out but are cost effective to use. This is for use on the aircraft as well as for ATS. Contractors will have a strong working relationship with the service ATS PGMs to develop the testing capability as new aircraft capability is developed.

Cross-service testing is becoming more common than in the past. When a repair workload is indentified as organic, it's quite common to have all the services look at and possibly bid on it, not just the same service repair centers. Frequently similar testing capabilities are needed with the current standard testers of each of the services. As time goes by, a significant portion of this test capability will become common to all the services, also known as purple. This includes increasing the types of standard testers beyond avionics testing, as well as some identical test capability within each service's current standard testers. An example of this might be a standard hydraulic tester.

Maturing and implementing more of the IEEE standards will standardize the approach to testing, how testing is performed, and result in cheaper, faster, better testing and repair for the Air Force.

\section{FAR FUTURE}

Very few parts will wear out due to components being manufactured with materials not yet identified. Fast and easy monthly or quarterly tests will be performed to ensure everything within the aircraft, ATS, or tester is working correctly. Aircraft BIT, BIST, and prognostics have replaced the need for most ATS. TPSs have evolved to where stimulus and measurement can be performed without cabling. Virtual instruments within testers allows for ease of instrument replacement.

\section{CONCLUSION}

The ATS community is working on spending less time and money supporting ATS so there will be more resources to support platforms. The management tools of the future will 
provide better and faster information on which ATS and AF platforms are healthy, which are not, as well as gaps in needed testing. Due to the times being austere, the defense spending pot will be shrinking for the foreseeable future. This is driving the services to invest in critical technology which will allow more flexibility for how and which ATS will be used in the future.

\section{ACKNOWLEDGMENT}

The authors of this paper wish to acknowledge Kevin Dusch and the other members of the DoD TPS Standardization IPT for their work on updating MIL-PRF-32070. We also wish to acknowledge Bill Ross, Marty Reagan, and PMA 260 for the DoD ATS website.

\section{REFERENCES}

[1] Expeditionary Combat Support System website https://www.ecss.wpafb.af.mil, ECSS Library, ECSS Fact Sheet "AFSO21, eLog21, and ECSS", March 2010.

[2] Logistics, Installations, and Mission Support - Enterprise View ,LIMSEV 101 Brief, http://www.acq.osd.mil//og/mpp/cbm+/Briefings/LIMSEV_OSD_CBMPlus_AG_Brief.pdf

[3] Item Unique Identification Implementation Toolkit, http://www.iuidtoolkit.com/
[4] Expeditionary Logistics for the 21st Century website, http://www.af.mil/information/elog21/index.asp

[5] DoD NxTest IPT ATS Framework Working Group' found on http://www.acq.osd.mil/ats

[6] Mar 2011 AMB Minutes

[7] IEEE Std 1232, Artificial Intelligence Exchange and Service Tie to All Test Environments (AI-ESTATE)

[8] IEEE Std 1636, Standard for Software Interface for Maintenance Information Collection and Analysis (SIMICA)

[9] IEEE Std 1641, Signal and Test Definition

[10] IEEE Std 1671, Automatic Test Markup Language (ATML) for Exchanging Automatic Test Equipment and Test Information via XML

[11] MIL-PRF-32070, "Performance Specification, Test Program Sets", Defense Printing Office website, ASSIST-Quick Search, https://assist.daps.dla.mil/quicksearch/

[12] Instructions for Modular Open Systems Approach (MOSA), DoD ATS website, http://www.acq.osd.mil/osjtf/pdf/MOSA_Jul04.pdf 